Bond University

Research Repository

\title{
An investigation into the relationship between long-term Posttraumatic Stress Disorder symptoms and coping in Australian volunteer firefighters
}

Doley, Rebekah M.; Bell, Ryan; Watt, Bruce D.

Published in:

Journal of Nervous and Mental Disease

DOI:

10.1097/NMD.0000000000000525

Licence:

Unspecified

Link to output in Bond University research repository.

Recommended citation(APA):

Doley, R. M., Bell, R., \& Watt, B. D. (2016). An investigation into the relationship between long-term

Posttraumatic Stress Disorder symptoms and coping in Australian volunteer firefighters. Journal of Nervous and Mental Disease, 204(7), 530-536. https://doi.org/10.1097/NMD.0000000000000525

\section{General rights}

Copyright and moral rights for the publications made accessible in the public portal are retained by the authors and/or other copyright owners and it is a condition of accessing publications that users recognise and abide by the legal requirements associated with these rights.

For more information, or if you believe that this document breaches copyright, please contact the Bond University research repository coordinator. 
[Type text]

An Investigation into the Relationship Between Long Term Post Traumatic Stress Symptoms and Coping in Australian Volunteer Firefighters

\begin{abstract}
Introduction: This study examined the relationship between coping style and long term posttraumatic stress symptoms in an Australian sample of volunteer firefighters 84 months following a bushfire disaster.
\end{abstract}

Methods: A total of 277 firefighters completed four questionnaires to assess patterns of psychiatric morbidity. A two-way repeated measures of analysis of variance was conducted to investigate the effect of time and disorder on coping.

Results: Firefighters evidencing distress were more likely to employ both problem and emotion focused methods of coping.

Discussion: Based on previous research, it was hypothesized that problem focused coping strategies would be employed after 84 months. The use of both problem and emotion focused coping may be due to the length of time following this disaster or unique characteristics of firefighters.

Conclusions: These data suggest that present coping theories are not sufficient to account for the onset and pattern of psychiatric morbidity within a firefighter sample.

The authors declare no conflicts of interest including financial, consultant, institutional, and other relationships that might lead to bias.

Keywords: 
Posttraumatic stress disorder; longitudinal studies; firefighters; disasters; coping

\section{Introduction}

Volunteer firefighting has been acknowledged to be one of the most dangerous and stressful occupations (Brough, 2004; Cook \& Mitchell, 2013). Several studies have noted protective factors attributable to the altruistic motivations of volunteer firefighters (McLennan \& Birch, 2005; Thompson \& Bono, 2006); despite this, however, volunteer firefighters have been found to have increased prevalence and incidence of a number of mental health concerns, including depression (Fullerton, Ursano, \& Wang, 2004), alcohol and substance use disorders (Bacharach, Bamberger, \& Doveh, 2008), as well as post-traumatic stress symptoms (Corneil, Beaton, Murphy, Johnson, \& Pike, 1999; Prati, Pietrantoni, \& Cicogani, 2011). Additionally, psychiatric morbidity has been found to worsen following a traumatic incident. For example, Tak, Driscoll, Bernard, and West (2007) found that depression and anxiety increased for firefighters responding to the Hurricane Katrina disaster of 2005. Increased incidence of posttraumatic stress disorder (PTSD) has been found among firefighters responding to a variety of traumatic duty-related incidents including the terrorist attacks of September 11, 2001 (Berninger et al., 2010), and the 2003 California wildfires (Jones, Ribbe, Cunningham, \& Weddle, 2003).

Studies investigating the development of post-traumatic stress symptoms among firefighters have focused mainly on immediate or short-term consequences following a disaster. The majority of research investigating the long-term course of post-traumatic stress symptoms for other populations has derived from studies of combat veterans (Link \& Palinkas, 2013; Zerach, Solomon, Horesh, \& Ein-Dor, 2013) and may not be generalisable to civilian samples. Agorastos et al. (2014) note that the type of traumatic experience may have an impact on the long-term course of post traumatic stress, and brief but intense exposures to 


\section{RELATIONSHIP BETWEEN PTSD AND COPING AMONG FIREFIGHTERS}

trauma (such as the experiences reported by firefighters responding to a natural disaster) may have more enduring effects than sustained trauma experienced by combat veterans.

The remaining studies investigating the long-term course of post-traumatic stress symptoms have examined civilian victims of natural disasters (Arnberg, Johannesson, \& Michel, 2013; Hussain, Weisaeth, \& Heir, 2011), and victims of personal injury or violence (Kulkarni, Graham-Bermann, Rauch, \& Seng, 2011; Kuwert et al., 2014). Brewin, Andrews, and Valentine (2000) argue that methodological differences between these studies renders direct comparisons between these groups difficult, with both rates of long term PTSD and identification of risk factors varying wildly. A number of factors have been identified that appear to predict a chronic course of post-traumatic stress following a traumatic event in several civilian populations including personal losses, personal exposure to the traumatic incident, personal injury, and perceived threat (Paul et al., 2014). McFarlane (1988d) found that none of these factors predicted the emergence of PTSD symptoms among a sample of firefighters 25 months after exposure to a traumatic event suggesting that the risk factors for the development of post-traumatic stress symptoms among firefighters may be unique to this population.

To date, the only research investigating the longitudinal course of post-traumatic stress symptoms among firefighters following a natural disaster is described in a series of studies conducted by McFarlane examining the long-term emotional impact of the Ash Wednesday Bushfire Disaster in South Australia among 469 volunteer firefighters at 4 (1985), 8 (1986), 11 (1987), 29 (1988a, 1988b, 1988c, \& 1988d), and 42 months (1989) after the event. Four months following the disaster, a subsample of firefighters exposed to the bushfires were distributed a survey pack containing the General Health Questionnaire (GHQ; Goldberg, 1972), a brief life events inventory, the Impact of Events Scale (IES; Horowitz, 
Wilner, \& Alvarez, 1979), and a demographic survey. The 496 firefighters who returned a usable response were mailed an additional questionnaire 11 months following the disaster examining the firefighters involvement in the fire service following the incident, their recovery from injury sustained during the fire, the nature of imagery experienced since the disaster, methods used to deal with memories of the disaster, and the firefighter's efforts to obtain professional assistance for stress related problems. The GHQ, brief life events inventory and the IES were also readministered. All firefighters who returned a usable response after 11 months were mailed a third questionnaire 29 months following the disaster that consisted of questions related to the firefighter's exposure to fires since the previous questionnaires, the characteristics of any post traumatic imagery, the past history of seeking psychological help. The GHQ, the brief life events inventory, and the IES were again readministered at this stage.

In total, 315 (67\%) firefighters returned completed questionnaires on all three occasions (McFarlane 1988c, 1988d, 1989). The GHQ was validated as an instrument for detecting PTSD within this sample via a series of clinical interviews with a subsample of participants 8 months after the fire. Using the GHQ, McFarlane found that 32\% of respondents exhibited symptoms consistent with a diagnosis of PTSD at 4 months, 27\% at 11 months, and 30\% at 29 months following the disaster (McFarlane, 1988d). Among all variables selected for analyses at the 11 and 29 month conditions, the only variables found to be partial predictors of morbidity patterns were adversity before the event, neuroticism, and a history of treated psychological disorders (McFarlane, 1988c, 1989). Additionally, the use of avoidant coping strategies (as measured by agreement that the best way to deal with the problem us to stop the self from thinking, an item on the impact of events scale) was found to be strongly associated with PTSD morbidity (McFarlane, 1988c), an interesting finding as it suggests that the coping strategies firefighters employ following a traumatic event are related 


\section{RELATIONSHIP BETWEEN PTSD AND COPING AMONG FIREFIGHTERS}

to the development of PTSD symptoms. While this finding was not explored in any further depth within this series of studies, other research has suggested that coping style plays an intervening role in the relationship between stress and adaptational outcome following a disaster (Christiansen, Hansen, Elklit, 2014; Huijts, Kleijn, Emmerik, Noordhof, \& Smith, 2012; Pineles et al., 2011).

To date, no other published study has explored the long-term course of stress symptoms among volunteer firefighters. This is particularly concerning in light of research conducted by Huizink et al. (2006) who found that, among a sample of 334 professional firefighters who responded to a 1992 Amsterdam plane crash, an increased prevalence of health and mental health complaints were observed 8.5 years after the disaster when compared to a matched comparison sample of unexposed firefighters. McFarlane (1989) reported that stress symptoms were a common concern among volunteer firefighters for up to 42 months following a disaster lending credence to the hypothesis that stress symptoms may persist for even longer timeframes. Research conducted by Kessler, Sonnega, Bromet, Hughes, and Nelson (1995) found that if symptoms of post-traumatic stress symptoms persist for longer than 72 months, the symptoms have a substantial probability of remaining chronic and, if volunteer firefighters report a high prevalence of symptoms for periods approaching or exceeding this time-frame, it may be appropriate to expand the scope and magnitude of psychological interventions designed to ameliorate this risk or to provide better access to mental health services many years following a disaster event.

\section{Coping and Post Traumatic Stress Disorder.}


Research on the relationship between coping strategies and psychological distress after a traumatic event has focused on two domains of coping: problem focused and emotion focused coping strategies (Glass, Flory, Hankin, Kloos, \& Turecki, 2009; Horwitz, Hill, \& King, 2013; Rantanen, Mauno, Kinnunen, \& Rantanen, 2011.) Problem focused coping strategies are broadly described as engaging in behaviours to overcome problems associated with the traumatic event. This is typically achieved by defining the problem, considering alternative solutions in terms of cost/benefits, seeking more information, and selecting a strategy to address the problem (Carroll, 2013). Emotion focused coping strategies are broadly described as directing effort toward regulating emotional responses to the stressful encounter (Brannon \& Feist, 2009). This is typically achieved by managing or mediating hostile feelings, finding ways to release pent up emotions or by distancing the self or finding ways to distract the self from emotions associated with the stressful event.

Some research has suggested that problem focused coping is more effective than emotion focused coping in terms of reducing negative emotional reactions to stressful events (Elwood, Hahn, Olatunji, \& Williams, 2009; Zeidner, 2005). North, Spitznagel, and Smith (2001) found that problem focused coping strategies were associated with decreased risk for the development of psychiatric disorders following exposure to a mass murder episode. Resick and Schnicke (1992) found that the use of behavioural-focused, problem-solving coping following a sexual assault was associated with lower levels of PTSD symptoms in a 12-month follow-up period. Coffey, Leitenberg, Henning, Bennett, and Jankowski (1996) found that avoidant methods of coping with trauma increased the likelihood of experiencing ongoing distress following an episode of dating violence, and Silver, Holman, McIntosh, Poulin, and Gil-Rivas (2002) found that efforts to employ emotionally avoidant coping strategies to manage negative emotions from trauma were associated with increased levels of 


\section{RELATIONSHIP BETWEEN PTSD AND COPING AMONG FIREFIGHTERS}

PTSD symptoms among victims of the terrorist attacks in the United States on September 11, 2001.

While avoidant coping strategies have been found to be associated with long term mental health problems, Schnider, Elhai, \& Gray (2007) have suggested that avoidant emotion focused coping strategies can be helpful in the short term following a traumatic event. Additionally, Penley, Tomaka, and Wiebe (2002), in a meta-analysis, concluded that the magnitude and direction of the relationship between coping strategies employed and the mental health consequences for an individual, was impacted more by the specific type and duration of the stressor than the specific coping strategies employed by an individual. In light of these findings, further research is clearly needed to investigate the extent to which coping style is related to mental health outcomes for firefighters following a traumatic event.

\section{Aims and objectives}

The current study is a follow-up of McFarlane's original sample of volunteer firefighters 84 months following the Ash Wednesday Bushfire Disaster. The Ash Wednesday Bushfire Disaster was a cluster of bushfires that occurred in the South-Eastern regions of Australia on 16th February, 1983. As a result of these fires, 28 people were killed and more than 1500 people were injured; as well, substantial amounts of forest, grazing land, and private property were damaged or destroyed, including sheep and cattle losses in excess of 250,000 animals. While the present data was collected and subsequently analysed in 1990, the long-term course of stress-related symptoms remains an under-researched area, particularly as it pertains to volunteer firefighters. Though bushfires pose a threat to life and property in virtually every country, they are particularly threatening in Australia due to the hot and dry climate and the relatively sparse population density of regional and remote areas; 
as a result, bushfires are one of the leading causes of deaths from disasters in Australia, with injuries from bushfires exceeding the number of injuries incurred from all other natural disasters combined (AIC, 2004).

Our first aim was to examine the impact of exposure to this disaster on a long-term basis (84 months) within this affected population, as well as finding predictors of negative mental health outcomes following this time span. McFarlane (1988d) concluded that poorer mental health outcomes among firefighters were associated with avoidant coping styles however no further investigation was conducted to explore the relationship between other styles of coping and mental health outcomes. Our second aim was to expand on these findings by determining whether avoidant, emotion, or the use of both (mixed) coping strategies predicted the presence of post traumatic symptoms during this period of review.

\section{Method}

\section{Participants}

In total, 404 volunteer firefighters, from an original sample of 495 firefighters identified by McFarlane (1985) as having participated in containing the fires of Ash Wednesday, were able to be located for follow-up and review. Of this sample, 277 volunteer firefighters (6 females and 271 males) returned completed questionnaires. The mean age of participants was 42.2 years (SD=10.6), 246 (89\%) were married, and 257 (93\%) were presently employed.

\section{Instruments}


The survey comprised four questionnaires and a brief demographic questionnaire in which the name, age, occupation, and marital status of each participant was collected. The entire survey pack required approximately 20 minutes to complete.

The General Health Questionnaire (GHQ-12; Goldberg, 1972). The GHQ was used to assess the level of non-psychotic psychiatric impairment within this sample. The 12item version was selected for this study due to its brevity and similar validity to the 30 -item GHQ (Henderson, Byrne, \& Duncan-Jones, 1981). The utility of the GHQ-12 as a tool for detecting the long term mental health impact of trauma within this sample was assessed by McFarlane (1988d). McFarlane administered the GHQ-12 in conjunction with a structured clinical interview to a sample of 49 volunteer firefighters from his sample. It was established that the GHQ-12 had a 90\% specificity, 78\% sensitivity, and a misclassification rate of $12 \%$, when used to detect PTSD according to the diagnostic criteria outlined in the Diagnostic and Statistical Manual-III (DSM-III; American Psychiatric Association, 1980) within this population. Due to changes in the diagnostic criteria for PTSD that have occurred between the DSM-III and the recently published DSM-V (American Psychiatric Association, 2013), we have used the cut-off criteria elucidated by McFarlane to evidence post-traumatic stress symptoms only as this criteria has not been validated to detect PTSD specifically according to contemporary criteria.

Impact of Events Scale (IES; Horowitz et al., 1979). The IES was used to assess the level of distress caused by the fire. The IES is a 15-item measure of post-trauma symptomology that measures both "intrusion" (i.e., intrusive-repetitive images and thoughts) and “avoidance” (i.e., attempts to dispel images and thoughts) following a traumatic event. The IES has been used to assess post-trauma stress symptomology with a variety of firefighting populations, including volunteer firefighters (McFarlane 1988), rural firefighters 
(Corneil et al., 1999), and urban firefighters (Beaton, Murphy, \& Johnson, 2005). For the present study, the 15-item scale was modified to focus on fire-related experiences. Four items were added, which address cognitive strategies to block traumatic memories: "I had fear that another bushfire would start," "I felt bad about not containing the bushfire," "I found myself feeling angry about the bushfire,” and "I felt guilty about how I suffered less than others in the bushfires.”

Ways of Coping Questionnaire (WOC; Folkman \& Lazarus, 1980). The WOC was used to assess the coping methods employed by this sample. The WOC is a 66-item instrument querying a participant's likelihood to utilise a particular coping method (e.g., ignoring a problem, exercising, criticising oneself) when dealing with a variety of challenging scenarios. Based on conceptual and empirical literature describing coping strategies commonly employed in a stressful situation, the WOC identifies eight broad coping strategies that respondents are likely to utilise in challenging scenarios, including one problem-focused coping strategy (i.e., attempting to resolve or diffuse the problem), six emotion-focused coping strategies (i.e., wishful thinking, self-isolation, self-blame, tension reduction, focusing on the positive, distancing), and one mixed factor containing both problem- and emotionfocused items (i.e., seeking social support). Higher scores within one domain indicates a greater likelihood of using that coping method during a stressful situation.

\section{Life Events Inventory: The List of Threatening Experiences (Brugha,}

Bebbington, Tennant, \& Hurry, 1985). The List of Threatening Experiences was used to assess for the presence of recent traumatic events that may impact the psychiatric well-being of each participant. The List of Threatening Experiences is a 12-item measure that determines whether a participant has experienced an event likely to cause moderate-to-severe long-term psychological harm (e.g., the termination of a close romantic relationship, the death of an immediate family member). In a study of a representative sample of an Australian non- 


\section{RELATIONSHIP BETWEEN PTSD AND COPING AMONG FIREFIGHTERS}

clinical population, Henderson et al. (1981) found that an average person might experience four to five of these events in the course of 12 months.

\section{Procedure}

Of the original 495 participants of McFarlane’s (1988) study, 404 participants could be located. A survey package containing all described questionnaires was mailed to each of the 404 participants with an outline of the research and a postage-paid return envelope. Three weeks following the original mail-out, a reminder letter with a second copy of all questionnaires was mailed to 246 participants who did not respond.

A total of 307 of the distributed questionnaires were returned, including 30 questionnaires which remained unopened, resulting in a total of 277 participants who returned usable surveys and were included in analyses.

\section{Results}

\section{Preliminary analyses}

Across all instruments, some item-level data was missing. Consequently, the total number of cases included in each statistical analysis varied according to the completeness of data. Results from two-tailed independent samples $t$ tests indicated no significant difference between this sample and the 495-participant sample described by McFarlane (1988) in IES score, $t(400)=0.32, p>.05$, GHQ score, $t(406)=0.22, p>.05$, or recent adverse life events score, $t(424)=0.22, p>.05$, suggesting that, although only 56\% of McFarlane’s original sample chose to participate in this study, the scores obtained by those participants are similar to the scores obtained by McFarlane’s 495-participant sample on these three measures. 
GHQ. A mean GHQ score of $1.57(\mathrm{SD}=2.7)$ was reported. Using the recommended cut-off score greater or equal to 2 (Goldberg, 1972), 75 (28\%) respondents evidenced symptoms of psychiatric impairment 84 months after the disaster. The impact of actual consequences of the disaster, recent adverse life events, and coping was investigated using a hierarchical multiple regression analysis. A summary of results is presented in Table 1 . The best predictor of psychiatric impairment, accounting for 17\% of the variance in GHQ scores, was recent adverse life events $(F(2,172)=34.74, \beta=.408, p<.001)$. In addition, the Intrusion sub-scale of the IES was a significant predictor of psychiatric impairment, accounting for $7 \%$ of the variance $(\mathrm{F}(3,171)=15.78, \beta=.276, p<.001)$.

\section{TABLE 1}

\section{Coping and Disorder}

Pattern of Recovery from Trauma. To investigate the effect of time and disorder on coping, a two-way repeated measures analysis of variance was conducted. For the purpose of this analysis, the disorder group was divided into three subgroups according to the chronicity of psychiatric impairment. Chronicity was determined by diagnosis according to clinical interviews reported by McFarlane (1988d) at 42 months following the disaster, in conjunction with score on the GHQ at 84 months. The Chronic group denoted those subjects who evidenced psychiatric impairment at 84 months and PTSD at 42 months $(n=14)$, the Resolved group denoted those subjects who evidenced no psychiatric impairment at 84 months but were diagnosed with PTSD at 42 months $(n=45)$, and the No Impairment group denoted those subjects who did not evidence either PTSD or psychiatric impairment on either occasion $(n=17)$. 


\section{RELATIONSHIP BETWEEN PTSD AND COPING AMONG FIREFIGHTERS}

Significant main effects of time and sub-group were found for both problem-focused and emotion-focused coping, and of time only for mix-focused coping. A summary of these results is presented in Table 2. Greater coping efforts overall were reported at 42 months than at 84 months. Using Tukey’s post hoc procedure with significance level of .05, it was found that the chronic group reported significantly higher scores for both problem-focused and emotion-focused coping than either the resolved or no impairment group. The means and standard deviations are presented in Table 3.

\section{TABLE 2}

\section{TABLE 3}

\section{Discussion}

Our first study aim was to investigate the impact of a disaster on a cohort of volunteer firefighters 84 months following the event, and to find predictors of negative mental health outcomes following this time span. Using the recommended cut-off scores for Psychiatric Impairment on the GHQ-12 (Goldberg, 1972), 28\% of respondents evidenced symptoms of psychiatric impairment 84 months following the disaster. This is similar to the rate reported by McFarlane (1988d) who found that, 42 months following the disaster, $29 \%$ of his sample qualified for a diagnosis of PTSD based on scores obtained on the GHQ-12. In spite of these findings, within this sample 45 participants who previously qualified for a diagnosis of PTSD at 42 months did not evidence any psychiatric impairment at 84 months, suggesting that these participants had either resolved their disorder or were members of the "recurrent chronic" group of participants identified by McFarlane as showing a fluctuating pattern of recovery. It is clear from our findings that negative health implications remain for some volunteer firefighters, even 84 months following a disaster event. With respect to coping, avoidance of 
intrusive images was a better predictor of coping response than was experience with intrusive representations.

These results have profound implications for government agencies who employ volunteer firefighters in the wake of a natural disaster. Though several studies have noted that firefighters comprise an at-risk group for the development of stress-related symptoms in the immediate aftermath of an event (Corneil et al., 1999; Prati et al., 2011), the present study highlights that these symptoms may have a greater chronicity than was previously demonstrated. While these findings underscore the importance of expanding existing mental health support services to firefighters exposed to a disaster for at least this period of time, it is important to note that volunteer firefighters may not have access to the same systems of support as professional firefighters. Several researchers have noted that volunteer emergency workers tend to have less access to employment-related counselling and psychological services (Thormar et al., 2010), less access to post-disaster social support (Dyregrov, Kristoffersen, \& Gjestad, 1996; Mitchell, Griffin, Stewart, \& Loba, 2004), and less experience with disaster work (Fullerton et al., 2004; Guo et al., 2004), than their professional counterparts. Unsurprisingly, volunteer firefighters evidence greater physical and mental health effects following a disaster (Hytten \& Hasle, 1989; Psarros, Theleritis, Martinaki, \& Bergiannaki, 2008); it is our hope that studies such as this can help underscore the importance of making mental health services available to volunteer organisations following a disaster.

Our second aim was to determine whether coping style can be used to predict posttraumatic symptoms following this period of review. In spite of prior literature suggesting that problem focused coping is more effective than emotion focused coping in terms of reducing negative emotional reactions to stressful events (Elwood et al., 2009; North et al., 2001; Zeidner, 2005), firefighters experiencing impairment after 84 months were more likely 


\section{RELATIONSHIP BETWEEN PTSD AND COPING AMONG FIREFIGHTERS}

to use both problem and emotion focused coping strategies more frequently than nondisordered participants. These findings are consistent with some research suggesting that emotion focused coping is associated with poorer mental health outcomes following a stressful event (Chung, Dennis, Berger, Jones, \& Rudd, 2011; Scrignaro, Barni, \& Magrin, 2011)

We expected that more use of problem focused coping will be evident at 84 months than at 42 months, regardless of the chronicity of disorder, based on White (1974), who described patterns of coping commonly seen in patients with severe injuries. White stated that, while emotion focused coping strategies are employed initially to control the emotions, this tends to transform to problem-focused coping with time, as an individual comes to terms with their trauma. A similar pattern of coping strategy use has been noted by (Gregorio, Gould, Spitz, von Heugten, \& Ponsford, 2014; Wong, Reker, \& Peacock, 2006). Within our sample, greater coping efforts were reported at 42 months than at 84 months, and coping efforts increased with increasing chronicity of disorder. No significant interaction between coping, disorder, and time was found. With respect to our hypothesis, greater use of problemfocused coping at 84 months was not found.

This pattern is inconsistent with the pattern of recovery posited by White (1974). This pattern of results may, however, have been influenced by the length of time which has passed since the disaster. The present study represents the longest-term study of trauma symptoms among firefighters, and it is possible that the pattern of recovery proposed by White may be evident only in the first 12 to 24 months following a traumatic event.

Concerns raised about the posited relationship between coping and adaptational outcome have pointed to the tendency for effective coping to be confounded with the 
outcome of coping (Penley, Tomaka, \& Wiebe, 2002; Schnider, et al., 2007). Effective coping has been described as involving greater use of problem-focused strategies. More contemporary research, however, has suggested that better adaptational outcome is associated with greater scope and a variety of responses, and the use of both emotion- and problemfocused coping (Elwood et al., 2009; Penley et al.).

It remains implicit in the literature that effective coping is most commonly expected to result in reduced distress through regulating emotions and attempting to solve problems causing distress. Accordingly, the term "better adaptational outcome” in these studies was used to describe participants with little to no psychiatric disturbance. The results of this study may contradict this assumption, however.

Previous coping theories have been based on research conducted using clinical populations or community-based samples that have been exposed to everyday stressors. The present study differs from previous research in that the sample was selected exclusively on the basis of exposure to a traumatic event. Thus, the trends evident from previous research may be difficult to generalise to the present population, and conclusions drawn from this study may not apply to clinical or other community samples.

\section{Limitations}

The term “psychiatric impairment” was used to describe participants who scored above the recommended cut-off score of 2 on the GHQ-12 however, of the firefighters surveyed at 84 months, 93\% were employed and $89 \%$ were married, suggesting that, although a number were suffering psychiatric impairment, they were still living as functional members of society. The psychological effort required to achieve this level of functioning likely necessitated an extraordinary level of coping behaviour and it may be argued that disordered individuals within this sample are employing effective coping strategies to achieve better 


\section{RELATIONSHIP BETWEEN PTSD AND COPING AMONG FIREFIGHTERS}

adaptational outcomes, as evidenced by their ability to remain in a non-clinical population while suffering from a psychiatric disorder. This interpretation questions the direction of the causal relationship between coping and psychiatric disorder posited above; among this sample, the relationship between effective coping and reduced stress is not supported. Consequently, an alternative model of the relationship between traumatic event, coping response, and adaptational outcome may be appropriate.

In terms of issues for future research, in this study the GHQ-12 was used to provide a measure of psychiatric distress. While this test has been extensively validated with Australian populations and has been validated for its utility as a tool for detecting PTSD according to criteria outlined by the DSM-III (American Psychiatric Association, 1980), its validity as an index of impairment in a repeated measures design has not been extensively investigated, particularly according to contemporary clinical diagnostic classifications. Of particular concern is the wording of the questions; items on the GHQ ask the respondent to compare themselves to how they "usually” feel. The definition of "usually," however, is left up to the respondent's discretion. The difficulty with repeated measures is that it is not possible to ascertain whether "usually" is referring to the same period of time for the individual on different occasions of assessment. The potential for GHQ scores to be influenced by changes in response style should be considered in future research using the GHQ as a self-report measure of psychiatric heath.

Additionally, due to the study design, the potential influence of other traumatic events occurring between the bushfire disaster and the time of data collection was not explored. Although we expect that the confounding influence of further trauma would be adequately controlled for with a sufficient population size, a number of retrospective studies have noted that exposure to trauma is a risk factor for exposure to future traumatic events (Cougle, 
Resnick, \& Kilpatrick, 2009; Orcutt, Erickson, \& Wolfe, 2002), and it may be possible that the impairment noted at 84 months was partially mediated by additional exposure to trauma among impaired participants from earlier follow-up periods. Further research might explore this potential link in more detail - perhaps through the collection of interview data where exposure to subsequent traumatic events is thoroughly explored.

Although previous statistical tests have highlighted the similarity -- when compared to the participant sample collected in earlier iterations of this series of studies -- in rates of adverse life events, psychiatric impairment, and impact of the fire, it is notable that this research had a response rate of $56 \%$ of the original cohort of firefighters. Due to the lengthy interval between the traumatic event and the data collection, a high rate of attrition is to be expected; however, it is impossible to determine, from the information provided, whether the $44 \%$ of the original sample who did not participate had further clinical impairment not captured within these results.

\section{Conclusion}

The interpretation of the main findings of this research challenges some current theories of coping. The unidirectional causal relationship between traumatic event, coping response, and adaptational outcomes was not supported by this study. The present study is unique, both in its selection of participant sample (a non-clinical volunteer firefighter sample) and in the length of time assessed between triggering event and data collection. Further research could focus on determining the extent to which the participant sample or length of time may impact the relationship trajectory between traumatic event and adaptational outcomes.

The present study represents a continuation of the longitudinal study described by McFarlane (1985, 1986, 1987, 1988a, 1988b, 1988c, 1988d, 1989), in which the psychiatric 


\section{RELATIONSHIP BETWEEN PTSD AND COPING AMONG FIREFIGHTERS}

disturbance and post-traumatic stress of a cohort of volunteer firefighters was assessed at 4, 11, 29, and 42 months following a disaster. A major finding of the current research was that, at 84 months following the same disaster, a core group of firefighters still report symptoms of psychiatric disturbance and symptoms of PTSD. Further investigation may focus on the extent to which this cohort reports similar symptoms 168 months following the disaster or later. A review of the literature suggests that few studies have been published examining the long-term mental health consequences for emergency workers responding to a disaster, and long-term studies could help shed light on the longitudinal course of long-term posttraumatic morbidity. 


\section{References}

Agorastos, A., Pittman, J. O. E., Angkaw, A. C., Nievergelt, C. M., Hansen, C. J., Aversa, L., ... Baker, D. G. (2014). The cumulative effect of different childhood trauma types on self reported symptoms of adult male depression and PTSD, substance abuse, and health-related quality of life in a large active-duty military cohort. Journal of Psychiatric Research, 58, 46-54. doi:10.1016/j.jpsychires.2014.07.014

American Psychiatric Association. (1980). Diagnostic and statistical manual of mental disorders: DSM-3. Washington, D.C: American Psychiatric Association.

American Psychiatric Association. (2013). Diagnostic and statistical manual of mental disorders: DSM-5. Washington, D.C: American Psychiatric Association.

Arnberg, F. K., Johannesson, K. B., \& Michel, P. O. (2013). Prevalence and duration of PTSD in survivors 6 years after a natural disaster. Journal of Anxiety Disorders, 27(3), 347-52. doi:10.1016/j.janxdis.2013.03.011

Australian Institute of Criminology (AIC). (2004). The cost of bushfires. Bushfire arson bulletin no. 2 . 


\section{RELATIONSHIP BETWEEN PTSD AND COPING AMONG FIREFIGHTERS}

Bacharach, S. B., Bamberger, P. A., \& Doveh, E. (2008) Firefighters, critical incidents, and drinking to cope: The adequacy of unit-level performance resources as a source of vulnerability and protection. Journal of Applied Psychology, 93(1), 155-169. doi: 10.1037/0021-9010.93.1.155

Beaton, R., Murphy, S., Johnson, C., \& Corneil, W. (2005). Coping responses and posttraumatic stress symptomatology in urban fire service personnel. Journal of Traumatic Stress, 12(2), 293-308. doi: 10.1023/A:1024776509667

Berninger, A., Webber, M. P., Cohen, H. W., Gustave, J., Lee, R., Niles, J. K., ... Prezant, D. J. (2010). Trends of elevated PTSD risk in firefighters exposed to the World Trade Center Disaster: 2001-2005. Public Health Report, 125, 556-566.

Brannon, L., \& Feist, J. (2009). Health Psychology: An Introduction to Behavior and Health (7th ed.). Belmont, CA: Wadsworth Pub Co.

Brewin, C. R., Andrews, B., \& Valentine, J. D. (2000). Meta-analysis of risk factors for posttraumatic stress disorder in trauma-exposed adults. Journal of Consulting and Clinical Psychology, 68, 748-766. doi: 10.1037/0022-006x.68.5.748

Brough, P. (2004). Comparing the influence of traumatic and organizational stressors on the psychological health of police, fire, and ambulance officers. International Journal of 
Brugha, T., Bebbington, P., Tennant, C., \& Hurry, J. (1985). The list of threatening experiences: A subset of 12 life event categories with considerable long-term contextual threat. Psychological Medicine, 15, 189-94.

doi: 10.1017/S003329170002105X

Carroll, L. (2013). Problem focused coping. Encyclopaedia of Behavioural Medicine, 1540-1. doi: 10.1007/978-1-4419-1005-9_1171

Christiansen, D. M., Hansen, M., Elklit, A. (2014). Correlates of coping styles in an adolescent trauma sample. Journal of Child and Adolescent Trauma, 7(2), 75-85. doi: 10.1007/s40653-014-0011-2

Chung, M. C., Dennis, I., Berger, Z., Jones, R., \& Rudd, H. (2011). Posttraumatic stress disorder following myocardial infarction: Personality, coping, and trauma exposure characteristics. The International Journal of Psychiatry in Medicine, 42(4), 393-419. doi: 10.2190/PM.42.4.e

Coffey, P., Leitenberg, H, Henning, K., Bennett, R. T., \& Jankowski, M. K. (1996). Dating violence: The association between methods of coping and women's psychological adjustment. Violence and Victims, 11, 227-38. 


\section{RELATIONSHIP BETWEEN PTSD AND COPING AMONG FIREFIGHTERS}

Cook, B., \& Mitchell, W. (2013). Occupational health effects for firefighters: The extent and implications of physical and psychological injuries. Centre of Full Employment and Equity. Viewed 20 January 2015, available at https://www.firecrisis.com.au/wpcontent/uploads/2013/02/CofFEE-report-Final.pdf

Corneil, W., Beaton, R., Murphy, S., Johnson, C., \& Pike, K. (1999). Exposure to traumatic incidents and prevalence of posttraumatic stress symptomatology in urban firefighters in two countries. Journal of Occupational Health Psychology, 4, 131-141. doi: 10.1037/1076-8998.4.2.131

Cougle, J. R., Resnick, H., \& Kilpatrick, D. G. (2009). A prospective examination of PTSD symptoms as risk factors for subsequent exposure to potentially traumatic events among women. Journal of Abnormal Psychology, 118(2), 405-11. doi: 10.1037/a0015370

Dyregrov, A., Kristoffersen, J. I., Gjestad, R. (1996). Voluntary and professional disaster workers: Similarities and differences in reactions. Journal of Trauma and Stress, 9, 541-555. doi: 10.1007/BF02103663

Elwood, L. S., Hahn, K. S., Olatunji, B. O., \& Williams, N. L. (2009). Cognitive 
vulnerabilities to the development of PTSD: A review of four vulnerabilities and the proposal of an integrative vulnerability model. Clinical Psychology Review, 29(1), 87100. doi: 10.1016/j.cpr.2008.10.002

Folkman, S., \& Lazarus, R. (1980). An analysis of coping in a middle-aged community sample. Journal of Health and Social Behaviour, 21, 219-39.

Fullerton, C. S., Ursano, R. J., \& Wang, L. (2004). Acute stress disorder, posttraumatic stress disorder, and depression in disaster or rescue workers. The American Journal of Psychiatry, 161, 1370-6. doi: 10.1176/appi.ajp.161.8.1370

Glass, K., Flory, K., Hankin, B. L., Kloos, B., \& Turecki, G. (2009). Are coping strategies, social support, and hope associated with psychological distress among Hurricane Katrina survivors? Journal of Social and Clinical Psychology, 28(6), 779-795. doi: 10.1521/jscp.2009.28.6.779

Gregorio, G. W., Gould, K. R., Spitz, G., van Heugten, C., \& Ponsford, J. L. (2014). Changes in self-reported pre- to postinjury coping styles in the first 3 years after traumatic brain injury and the effects on psychosocial and emotional functioning and quality of life. Journal of Head Trauma Rehabilitation, 29(3), 43-53. doi: 10.1097/HTR.0b013e318292fb00

Goldberg, D. (1972). The detection of psychiatric illness by questionnaire. London: Oxford University Press.

Guo, Y.J., Chen, C.H., Lu, M.L., Tan, H.K., Lee, H.W., \& Wang, T.N. (2004). Posttraumatic stress disorder among professional and non-professional rescuers involved in an 


\section{RELATIONSHIP BETWEEN PTSD AND COPING AMONG FIREFIGHTERS}

earthquake in Taiwan. Psychiatry Research, 127(1-2), 35- 41. doi:

10.1016/j.psychres.2004.03.009

Henderson, S., Byrne, D. G., \& Duncan-Jones, P. (1981). Neurosis and the social environment. New York: Academic Press.

Horwitz, A. G., Hill, R. M., \& King, C. A. (2013). Specific coping behaviors in relation to adolescent depression and suicidal ideation. Journal of Adolescence, 34(5), 1077-85. doi:10.1016/j.adolescence.2010.10.004

Horowitz, M., Wilner, N., \& Alvarez, W. (1979). Impact of event scale: Measure of subjective stress. Psychosomatic Medicine, 41, 209-18.

Huijts, I., Kleijn, W. C., Emmerik, A. A., Noordhof, A., Smith, A. J. M. (2012). Dealing with man-made trauma: The relationship between coping style, posttraumatic stress, and quality of life in resettled, traumatized refugees in the Netherlands. Journal of Traumatic Stress, 25(1), 71-8. doi: 10.1002/jts.21665

Huizink, A. C., Slottje, P., Witteveen, A. B., Bijlsma, J. A., Twisk, J. W. R., Smidt, N., ... Smid, T. (2006)). Long term health complaints following the Amsterdam Air Disaster in police officers and fire-fighters. Occupational and Environmental Medicine, 63, 657-62. doi: 0.1136/oem.2005.024687

Hussain, A., Weisaeth, L., \& Heir, T. (2011). Psychiatric disorders and functional impairment among disaster victims after exposure to a natural disaster: A population based study. 
Journal of Affective Disorders, 128(1-2), 135-41. doi:10.1016/j.jad.2010.06.018

Hytten, K., \& Hasle, A. (1989). Fire fighters: a study of stress and coping. Acta Psychiatrica Scandinavica, 80(s355), 50-55. doi: 10.1111/j.1600-0447.1989.tb05253.x

Jones, R. T., Ribbe, D. P., Cunningham, P., \& Weddle, J. D. (2003). Psychosocial correlates of wildfire disaster: Post disaster adult reactions. Fire Technology, 39, 103-117. doi: 10.1023/A:1024229812303

Kessler, R. C., Sonnega, A., Bromet, E., Hughes, M., Nelson, C. B. (1995). Posttraumatic stress disorder in the national comorbidity survey. Archives of General Psychiatry, 52(12), 1048-60. doi: 10.1001/archpsyc.1995.03950240066012

Kulkarni, M. R., Graham-Bermann, S., Rauch, S. A. M., \& Seng, J. (2011). Witnessing versis experiencing direct violence in childhood as correlates of adulthood PTSD. Journal of Interpersonal Violence, 26(6), 1264-81. doi: 10.1177/0886260510368159

Kuwert, P., Glaesmer, H., Eichhorn, S., Grundke, E., Pietrzak, R. H., Freyberger, H. J., \& Klauer, T. (2014). Long-term effects of conflict related sexual violence compared with non-sexual war trauma in female World War II survivors: A matched pairs study. Archives of Sexual Behaviour, 43(6), 1059-64. doi: 10.1007/s10508-014-0272-8

Link, P. E., \& Palinkas, L. A. (2013). Long-term trajectories and service needs for military families. Clinical Child and Family Psychology Review, 16(4), 376-93. doi: 10.1007/s10567-013-0145-z

McFarlane, A. C. (1985). The effects of stressful life events and disasters: Research and theoretical issues. Australia New Zealand Journal of Psychiatry, 19, 409-421. 


\section{RELATIONSHIP BETWEEN PTSD AND COPING AMONG FIREFIGHTERS}

doi: $10.3109 / 00048678509158849$

McFarlane, A. C. (1986). Posttraumatic morbidity of a disaster: A study of cases presenting for psychiatric treatment. The Journal of Nervous and Mental Disease, 174, 1-11. doi: 10.1097/00005053-198601000-00002

McFarlane, A. C. (1987). Life events and psychiatric disorder: The role of a natural disaster. British Journal of Psychiatry, 151, 362-7. doi: 10.1192/bjp.151.3.362

McFarlane, A. C. (1988a). Relationship between psychiatric impairment and a natural disaster: The role of distress. Psychological Medicine, 18, 129-39. doi: 10.1017/S0033291700001963

McFarlane, A. C. (1988b). The phenomenology of posttraumatic stress disorders following a natural disaster. Journal of Nervous and Mental Disease, 176, 22-9. doi: 10.1097/00005053-198801000-00003

McFarlane, A. C. (1988c). The aetiology of posttraumatic stress disorders following a natural disaster. British Journal of Psychiatry, 152, 116-21. doi: 10.1192/bjp.152.1.116

McFarlane, A. C. (1988d). The longitudinal course of posttraumatic morbidity: The range of outcomes and their predictors. Journal of Nervous and Mental Disease, 176, 30-9. doi: 10.1097/00005053-198801000-00004 
McFarlane, A C. (1989). The aetiology of post-traumatic morbidity: Predisposing, precipitating, and perpetuating factors. British Journal of Psychiatry, 154, 221-8. doi: 10.1192/bjp.154.2.221

McLennan, J., \& Birch, A. (2005). A potential crisis in wildfire emergency response capability? Australia's volunteer firefighters. Society, Safety and Bushfires - Research from the Australian Bushfire Cooperative Research Centre, 6(2), 101-7. Doi: 10.1016/j.hazards.2005.10.003

Mitchell, T.L., Griffin, K., Stewart, S.H., \& Loba, P. (2004). We will never ever forget: The Swissair flight 111 disaster and its impact on volunteers and communities. Journal of Health Psychology, 9(2), 245-262. doi: 10.1177/1359105304040890

North, C. S., Spitznagel, E. L., \& Smith, E. M. (2001). A prospective study of coping after exposure to a mass murder episode. Annals of Clinical Psychiatry, 13, 81-7. doi: 10.3109/10401230109148952

Orcutt, H. K., Erickson, D. J., \& Wolfe, J. (2005). A prospective analysis of trauma exposure: The mediating role of PTSD symptomatology. Journal of Traumatic Stress, 15(3), 259-55. doi: 10.1023/A:1015215630493

Paul, L. A., Price, M., Gros, D. F., Gros, K. S., McCauley, J. L., Resnick, H. S. ... Ruggiero, K. J. (2014). The associations between loss and posttraumatic stress and depressive symptoms following Hurricane Ike. Journal of Clinical Psychology, 70(4), 322-32. 


\section{RELATIONSHIP BETWEEN PTSD AND COPING AMONG FIREFIGHTERS}

doi: 10.1002/jclp.22026

Penley, J. A., Tomaka, J., \& Wiebe, J. S. (2002). The association of coping to physical and psychological health outcomes: A meta analytic review. Journal of Behavioural Medicine, 25(6), 551-603. doi: 10.1023/A:1020641400589

Pineles, S. L., Mostoufi, S. M., Ready, B. C., Street, A. E., Griffin, M. G., \& Resick, P. A. (2011). Trauma reactivity, avoidant coping, and PTSD symptoms: A moderating relationship? Journal of Abnormal Psychology, 120(1), 240-6. doi: 10.1037/a0022123

Prati, G., Pietrantoni, L., \& Cicognani, E. (2011). Coping strategies and collective efficacy as mediators between stress appraisal and quality of life among rescue workers. International Journal of Stress Management, 18, 181-95. doi: 10.1037/a0021298

Psarros, C., Theleritis, C.G., Martinaki, S., \& Bergiannaki, I.D. (2008). Traumatic reactions in firefighters after wildfires in Greece. Lancet, 371(9609). doi: 10.1016/S01406736(08)60163-4

Rantanen, M., Mauno, S., Kinnunen, U., \& Rantanen, J. (2011). Do individual coping strategies help or harm in the work-family conflict situation? Examining coping as a moderator between work-family conflict and well-being. International Journal of Stress Management, 18(1), 24-48. doi: 10.1037/a0022007 
Resick, P. A., \& Schnicke, M. K. (1992). Cognitive processing therapy for sexual assault victims. Journal of Consulting and Clinical Psychology, 60(5), 748-56. doi: 10.1037/0022-006X.60.5.748

Schnider, K. R., Elhai, J. D., \& Gray, M. J. (2007). Coping style use predicts posttraumatic stress and complicated grief symptom severity among college students reporting a traumatic loss. Journal of Counseling Psychology, 54(3), 344-50. doi: 10.1037/00220167.54.3.344

Scrignaro, M., Barni, S., \& Magrin, M. E. (2011). The combined contribution of social support and coping strategies in predicting post-traumatic growth: A longitudinal study on cancer patients. Psycho-Oncology, 20(8), 823-31. doi: 10.1002/pon.1782

Silver, R. C., Holman, E. A., McIntosh, D. N., Poulin, M., Gil-Rivas, V. (2002). Nationwide longitudinal study of psychological responses to September 11. Journal of the American Medical Association, 10, 1235-44. doi: 10.1001/jama.288.10.1235

Tak, S., Driscoll, R., Bernard, B., \& West, C. (2006). Depressive symptoms among firefighters and related factors after the response to Hurricane Katrina. Journal of Urban Health, 84, 153-61. doi: 10.1007/s11524-006-9155-1

Thompson, A. M., \& Bono, B. A. (2006). Work without Wages; the Motivation for Valunteer Firefighters. American Journal of Economics and Sociology, 52(3), 323-43. doi: 10.1111/j.1536-7150.1993.tb02553.x

Thormar, S. B., Gersons, B. P. R., Juen, B., Marschang, A., Djakababa, M. N., \& Olff, M. (2010). The Mental Health Impact of Volunteering in a Disaster Setting: A Review. 


\section{RELATIONSHIP BETWEEN PTSD AND COPING AMONG FIREFIGHTERS}

Journal of Nervous and Mental Disease, 198(8), 529-38. doi:

10.1097/NMD.0b013e3181ea1fa9

White, R. W. (1974). Strategies of adaptation: An attempt at systematic description. In G. Coelho, D. Hamberg, \& J. Adams (Eds.), Coping and Adaptation (pp. 47-68). New York: Basic Books.

Wong, P. T. P., Reker, G. T. \& Peacock, E. (2006). The resource-congruence model of coping and the development of the Coping Schemas Inventory. In Wong, P. T. P., \& Wong, L. C. J.(Eds.), Handbook of Multicultural perspectives on stress and coping. New York: Springer.

Zeidner, M. (2005). Contextual and personal predictors of adaptive outcomes under terror attack: The case of Israeli adolescents. Journal of Youth and Adolescence, 34, 45970. doi: 10.1007/s10964-005-7263-y

Zerach, G., Solomon, Z., Horesh, D., \& Ein-Dor, T. (2013). Family cohesion and posttraumatic intrusion and avoidance among war veterans: A 20-year longitudinal study. Social Psychiatry and Psychiatric Epidemiology, 48(2), 205-14. doi: 10.1007/s00127-012-0541-6 